\title{
Abjeção, Afetos e Desejos no Mundo Globalizado: Construindo sentidos a partir de SHORTBUS, DE JOHN CAMERON MITCHELL (2006)
}

Abjection, AfFects ANd Desires in the Globalized World: BUILDING SENSES From SHORTBus, by John Cameron Mitchell (2006)

Miguel Rodrigues de Sousa Neto* miguelrodrigues.snetto@gmail.com

Aguinaldo Rodrigues Gome*** aguinaldorod@gmail.com

RESUMO: Distintos realizadores, geralmente independentes, têm lançado desde a última década do século passado uma cinematografia na qual são positivadas personagens e experiências marcadas por sua corporeidade, seu erotismo e/ou por suas performances de gênero. Assim, tomamos Shortbus, de J. C. Mitchell (2006), como representante desse conjunto mais amplo de trabalhos e buscamos compreender como afetos e desejos são os elementos definidores das personagens e conflitos ali elaborados, tomando a produção artística em seus aspectos históricos e políticos.

PalaVRAS ChAVE: Performances de Gênero, Sexualidade, Shortbus.

ABSTRACT: : Different directors, usually independent, has released since the last decade of the XXth century a cinematography in which characters and experiences marked by their corporeality, their eroticism and/or their performances of gender are positived. Thus, we take Shortbus by J. C. Mitchell (2006), as representative of this larger set of works and seek to understand how affections and desires are the defining elements of the characters and conflicts elaborated in this movie, taking artistic production in its historical and political aspects.

KEYWORDS: Gender performances, Sexuality, Shortbus.

\section{Sujeitos e abjeção na contemporaneidade}

Os sujeitos, individuais e coletivos, são constituídos por múltiplas personas, desenvolvidas no contato com o Outro. Há atravessamentos étnicos, de classe, da orientação dos desejos eróticos, de como são performados os gêneros nos corpos e relações. A partir de tais marcadores, juntamente com outros tantos, os sujeitos ocupam lugares na sociedade em que estão inseridos. Por vezes, subalternizados, em outras condições, estabelecemos parcerias, ou infligindo algum tipo de violência a outrem.

\footnotetext{
* Doutor em História Social pela Universidade Federal de Uberlândia. Docente do Curso de História do Campus de Aquidauana da Universidade Federal de Mato Grosso do Sul. Líder do Universo Dialógico - Grupo de Pesquisa em Linguagens \& Diferenças e coordenador do Laboratório de Estudos em Cultura \& Diversidade, Política \& Sexualidade - LabDiS.

** Doutor em Filosofia e História da Educação pela Universidade Estadual de Campinas. Docente do Curso de História do Campus de Aquidauana da Universidade Federal de Mato Grosso do Sul e do Programa de PósGraduação em Educação do Campus de Rondonópolis da Universidade Federal de Mato Grosso.
} 
Desnaturalizar os processos de constituição dos sujeitos e as relações havidas entre eles é uma tarefa árdua, porque cotidiana e baseada na compreensão dos usos do poder, expressos na violência, na desigualdade, na exclusão, na eliminação física.

Os cotidianos processos de hierarquização, exclusão, violência, de estabelecimento de relações tão assimétricas que se tornam tanatológicas, se baseiam, com frequência assustadora, na orientação do desejo erótico e afetivo e nas performances de gênero. Para que isso ocorra, é necessário que se transforme o "outro" em "algo", um objeto. É preciso que uma vida seja transformada em não-vida, ou seja, em uma vida que não merece ser vivida. É preciso transformar tais sujeitos em seres abjetos:

Hay en la abyección una de esas violentas y oscuras rebeliones del ser contra aquello que lo amenaza y que le parece venir de un afuera o de un adentro exorbitante, arrojado al lado de lo posible y de lo tolerable, de lo pensable. Alli está, muy cerca, pero inasimilable. Eso solicita, inquieta, fascina el deseo que sin embargo no se deja seducir. Asustado, se aparta. Repugnado, rechaza, un absoluto lo proteje del opróbio, está orgulloso de ello y lo mantiene. Y no obstante, al mismo tiempo, este arrebato, este espasmo, este salto es atraído hacia otra parte tan tentadora como condenada. Incansablemente, como un búmerang indomable, un polo de atracción y de repulsión coloca a aquel que está habitado por él literalmente fuera de si. (KRISTEVA, 2006, p. 7)

Os grupos hegemonicamente instalados em nossa sociedade global têm se esmerado por garantir que uma dada versão de sujeito, baseado em seu desejo e sua performance de gênero, possa existir. Esse sujeito ideal tem seu gênero, ou seja, a construção sócio histórica de sua masculinidade ou feminilidade, acoplado de maneira direta ao seu sexo biológico, de maneira que um macho da espécie seja levado a performar masculinidade, e a fêmea, por conseguinte, feminilidade. O desejo de um deve ser orientado para outro, complementarmente. Isso será expresso na ideia de família, nos contratos jurídicos (de casamento, herança, etc.); será ensinado nas escolas, pregado nos púlpitos.

Aquelas e aqueles que divergem desse sujeito ideal são tornados abjetos. A abjeção leva a violência, exclusão, morte. Sendo abjetos, não há questionamentos éticos a serem feitos quando se pratica violência, quando se assassina. Talvez por isso as imagens do assassinato da travesti Dandara dos Santos, em 15 de fevereiro de 2017, em Fortaleza, no Ceará, tenha impressionado pouco e sido motivo de riso para aqueles que participaram do ato (POLÍCIA INVESTIGA HOMICÍDIO, G1, 2017). Uma vida que não merecia ser vivida - e o 
que a tornava abjeta era sua performance feminina, tendo nascido do sexo masculino. Podemos juntar a isso tratar-se de uma pessoa demasiado empobrecida.

Enfrentar essa abjeção e a violência, a invisibilização, o apagamento e a morte que dela advém é uma tarefa que, nalguma medida, se transforma em modo de vida, porque se efetiva como resistência cotidiana, perpassando os movimentos sociais (organizados e difusos), a produção artística, a academia, entre tantos setores.

Essa atuação constante se avoluma, no tempo presente, face ao levante, antes silencioso e cada vez mais estridente, dos setores reacionários e de ultradireita em níveis globais, tais como a ocupação cada vez maior do Partido Popular Suíço no parlamento, o que também ocorre na Dinamarca, Hungria, Áustria, Finlândia; (OS SEIS PARTIDOS, O GLOBO, 2017) as disputas mais acirradas na nação que fez transbordar para além de seus limites o estado liberal, a partir de figuras como Marine Le Pen, ou aquela que parecia insólita vitória de Donald Trump para a presidência dos Estados Unidos da América em 2016. No Brasil, as movimentações jurídico-políticas que retiraram do poder a presidenta Dilma Rousseff fizeram com que os setores mais conservadores ocupassem paulatinamente as agendas do executivo, do legislativo e do judiciário, não bastasse o loteamento violento do Estado pelo capital. Neste processo a imagem de Dilma Rousseff foi paulatinamente abjetificada. Embora os discursos, em sua maioria, fossem pautados pelo fim da corrupção, nos jornais (impressos, televisionados, virtuais) apareceu com frequência associação entre sua condição de mulher e uma suposta incompetência e corruptibilidade, demonstrando que a política também sofre atravessamentos da categoria gênero (LEAL, 2015). Assim, o que se pode observar, foi um ataque aos direitos humanos em suas múltiplas dimensões, mascarado apenas por outros fatores. Tanto que, finalizado esse processo, foi necessário encontrar outros alvos de abjeção, que parecem ser dois, quais sejam, a prática educacional e a produção artística, considerando a apresentação e aprovação de "leis da mordaça" que impedem que gênero ocupe espaço nas escolas e os abusivos fechamentos de exposições ou apresentações artísticas que tratam do mesmo tema, como ocorrido com a exposição "Queer Museu - Cartografias da Diferença na Arte Brasileira", cancelada pelo Santander Cultural em Porto Alegre, em setembro de 2017 (APÓS PROTESTO, FSP, 2017), e a performance "La bête", de Wagner Schwartz no Museu de Arte Moderna de São Paulo, 
judicilizada em razão da nudez pública do artista em sala com presença de crianças (INTERAÇÃO DE CRIAÇÃO, G1, 2017).

Esse movimento persecutório desenvolvido pelos setores reacionários e conservadores já havia sido exposto pelo docente da Universidade Estadual de Campinas Jorge Coli, a partir de censura a trechos e imagens de sua conferência ocorrida na Academia Brasileira de Letras, ainda em 2012.

Ontem, dei uma conferência na Academia Brasileira de Letras, intitulada "Sexo não é mais o que era". Tratava-se de uma análise reflexiva sobre as noções de pornografia, erotismo e sexualidade nas artes. Ela sublinhava o caráter conservador do moralismo atual e criticava os puritanismos repressivos que oprimem o imaginário, e não apenas ele. A conferência deveria ter sido transmitida via internet. Soube hoje que ela foi censurada, e que essa censura teria vindo por "ordem da diretoria". De início, as imagens que a ilustravam foram suprimidas da transmissão (eu começava com duas obras de Jeff Koons). E, quando citei o trecho de um autor que continha algumas palavras indelicadas (crítica de Philippe Murray ao quadro de Courbet, A origem do mundo, publicada em 1991 na revista Art Press), a palestra foi interrompida. Ou seja, a ABL ilustrou, de modo preciso, o acerto de minha tese sobre a hipocrisia putibunda (termo no qual certamente ela ainda censurará as duas últimas sílabas) de nosso tempo. Não apenas os acadêmicos são imortais: eles também não têm sexo, como os anjos. (COLI, 2013, p. 450-451)

Se, naquele momento, a repercussão do fato foi relativamente pequena, ocupando apenas jornais impressos e virtuais em poucas referências, nos últimos dois anos a censura à expressão artística e ao pensamento acadêmico - sobretudo àqueles voltados ao gênero, sua performatividade e aos direitos individuais e coletivos - tem sido intensificada.

Nessa conjuntura a arte têm sido objeto de ataque, na medida em que outras formas de aglutinação parecem não mais surtir efeito. E é preciso resistir.

A MC Linn da Quebrada, nascida numa das regiões pobres da cidade de São Paulo e criada por sua mãe no seio de uma expressão religiosa cristã conservadora, conhecida a partir do sucesso de seu vídeo "Enviadescer", publicado na plataforma YouTube em meados de 2016, abre sua entrevista ao canal Trip TV (no mesmo sítio virtual), afirmando: "Eu faço música pra ser ouvida, eu não faço pra ser cantora" (MC Linn da Quebrada, Trip TV). A arte, então, é utilizada para diretamente dialogar com o corpo social, como continua a afirma a MC:

A nossa estética e o que eu faço é uma experimentação estética radical. 0 espelho foi um elemento fundamental em minha trajetória. Eu via no 
espelho a expectativa de outras pessoas. As pessoas esperavam que eu fosse um homem feito à imagem e semelhança de deus. Até o momento em que eu como do fruto da árvore do conhecimento do que é bom e do que é mal, e decido eu mesma decidir o que é bom e o que é mal pra mim. Então sou expulsa do Éden. (...) E passo então a perambular pelo mundo, a transitar, pra me conhecer.

Assim, a artista considera os múltiplos aspectos da produção estética, incluso sua capacidade de interação com o corpo social. Nós podemos compreender dialogicamente o mundo por meio da razão filosófica, por meio das ciências, por meio da fruição estética, ao mesmo tempo em que nele atuamos, constituindo-o. São meios legítimos, e distintos. Cada sujeito elabora, a partir de suas experiências e necessidades, sua obra, conflituando ali o mundo no qual se insere, e a entrega ao público, que dela se apropria, ignora, refuta. Cada sujeito se insere e interfere no corpo social, corpo esse cada vez mais alargado, na medida em que nos tornamos uma sociedade global.

A arte pode reforçar pontos de vista e estéticas hegemonicamente elaborados e publicizados, ou, pode elaborar outras perspectivas e experiências distintas e que são representativas de outros corpos, performances dos gêneros e sexualidades. Pode também expressar outros afetos, como aqueles homoeroticamente inclinados amalgamados por Mário de Andrade no seu protagonista Frederico Paciência, nos anos 1940) (ANDRADE, 1947); e outras experiências, como aquela empobrecida e racializada de Carolina Maria de Jesus, da qual tomamos conhecimento em 1960 por meio de seu diário de uma favelada. Mário já estava morto quando o conto foi publicado e Carolina precisou ser "encontrada" por Audálio Dantas, jornalista da extinta revista Realidade (JESUS, 1960; MARÃO, 2010).

Pelas artes, fruímos. Observamos o mundo, gozamos dele, por meio daquilo que foi elaborado por outras mãos, outros olhos e olhares, outras mentes. Apreendemos o mundo em sua diversidade pela produção artística. Daí precisarmos de arte. A razão tem seus limites, assim como as ciências, ao lado delas, também é preciso sentir. Sentindo, por vezes trilhamos caminhos desconhecidos até então. Trilhando, continuamos nossas trajetórias de inserção no mundo, enquanto mudamos a nós e o transformamos, porque ambos estamos lançados nesse longo processo de não permanência, de mutabilidade. E a esse processo tem-se oposto algumas permanências nefastas à construção de uma sociedade global menos injusta, menos violenta, menos excludente. 
Buscamos compreender determinados aspectos dessa sociedade globalizada por meio de uma representação fílmica, a partir de questões que passamos a elucidar. Não há aqui qualquer pretensão de falar em nome de outrem, quando tomamos obras ou falas. Também, ao fazê-lo, não damos voz a ninguém, ouvimos o que já foi dito, dialógica e interpretativamente. As únicas vozes conscientemente colocadas aqui, ao lado destas outras, por fim, são as nossas, que também somos sujeitos nesta sociedade global, e, por meio do que escrevemos, pretendemos nos fazer ouvir, porque também fazemos apostas e lançamos os dados sobre um feltro que nem sempre é verde, mas quase sempre manchado, puído, riscado, esburacado.

Ora, desejos e afetos são criações histórico-culturais do corpo social, e, em razão mesmo disso, são objeto tanto de idealização e apoio, quanto de interdição, conforme a conjuntura vivida em cada sociedade. Se tomamos distintos grupos humanos para observálos mais de perto, encontramos ali e aqui tabus, prescrições, ritos. As performances de gênero também são objeto de regulação e interdição. O modelo hegemonicamente instalado na sociedade globalizada contemporânea é aquele binário, no qual temos o homem de um lado (e um pouco acima) e a mulher de outro (e um pouco abaixo...). E, apesar de uma assimetria historicamente elaborada, esses seres devem desejar um ao outro, mantendo a heterossexualidade, tornada compulsória. É tempo de questionar normatividades hegemônicas que insistem em nos delimitar corpórea e socialmente a partir do binarismo de gênero que impacta sobretudo nossas performances sexuais. Apesar da aparente liberdade conseguida pós década de 1960, vivemos, ainda hoje, do ponto de vista sexual, tempos fraturados. Lida-se precariamente com a construção subjetiva atravessada pelo desejo e pela performatividade dos gêneros, já que ainda somos atravessados pelo binarismo da norma e do desvio. Como afirma Swain, ainda insistimos em fazer uma interpretação binária do mundo:

não somente em relação aos sexos, homem/mulher (na ordem), mas igualmente quanto a visão dualista do que compõe a inteligibilidade da vida: o bem e o mal, o bom e o mau, o real e o imaginário, o puro e o impuro, o claro e o obscuro, o verdadeiro e o falso, o belo e o feio, o espírito e a matéria, a vida e a morte. (SWAIN, 2001, p. 89)

Mesmo na contemporaneidade temos, ainda, certa tendência em nos posicionarmos nos limites do binarismo, ao nos organizarmos economicamente, quanto aos usos do espaço público, e também quanto aos usos e significados de nós mesmos. As 
experiências político-estéticas de grupos não hegemônicos que reivindicam a possibilidade de ruptura com esquema binário têm sido caras para questionar a sexualidade fora da díade norma e desvio, e isso parece estar representado no filme Shortbus, de John Cameron Mitchell.

É preciso considerar a ambiguidade e/ou os paradoxos que marcam tal processo. Por um lado, tem-se hoje a possibilidade de experimentações eróticas e estéticas não binárias, constituindo um vasto repertório de identidades e performances eróticogenerificadas, o que tem podido ser realizado em espaços específicos, normalizados pelo próprio capitalismo, seja in loco, como nas saunas, bares, casas noturnas, happenings, etc., ou virtuais, como salas de bate-papo ou aplicativos de busca por encontros erótico-afetivos, sendo territórios ambivalentes que permitem, simultaneamente, o exercício da liberdade e uma forma de segregação mercantilizada. De outro, o exercício político destas performances não se efetiva no espaço público, haja vista observarmos neste a violência, o silenciamento, a transformação da diferença em fator de desigualdade e, em última instância (mas, cotidianamente), de morte. Ou seja, o exercício político das performances atravessadas pelos gêneros e pelo desejo não foram transformados em direitos por esta mesma sociedade liberal, globalizada e capitalista.

Refletir sobre e a partir de um objeto estético - um filme - integra as ações que imaginamos serem possíveis e desejáveis no contexto da academia numa sociedade globalizada. Para tanto, explicitaremos alguns poucos aspectos dos tantos que nele nos impactam, inserindo-os no tempo e no espaço permeáveis da conjuntura globalizada de sua produção.

O ponto que abordaremos é simples na sua formulação, qual seja: em um período marcado pela dissolução de laços entre sujeitos e grupos, denominado por Gilles Lipovetsky como a Era do Vazio (LIPOVETSKY, 2005, p. 17ss), o diretor e roteirista estadunidense John Cameron Mitchell, em diálogo com um pequeno grupo de atores, aposta estética e politicamente na necessidade e na possibilidade de conexão entre sujeitos pelos afetos e pelo desejo, em suas múltiplas expressões e formas (RICH, 1992).

\section{Afetos líquidos}


Zygmunt Bauman (2001; 2004) fez-se arauto da modernidade líquida. Foi o proclamador de um diagnóstico importante: no período que sucede aos grandes conflitos do século XX - da primeira Grande Guerra até o início da Guerra Fria -, a sociedade global teria submergido em uma modernidade líquida, caracterizada por um encurtamento sem precedentes das distâncias (entre nações, grupos sociais, sujeitos) e cujas relações havidas a partir de então seriam dinâmicas, fluidas, voláteis. Novas identidades, rapidamente substituídas. Novos afetos, igualmente deixados de lado - ou para trás - em favor de tantos outros a serem iniciados.

Em tal sociedade estruturada por transformações tecnológicas - que não alteram apenas o trabalho, a produção, a economia -, o entretenimento (SEVCENCKO, 2001, p. 75ss) e a fruição seriam igualmente modificados. O novo mundo atravessando a mimese, o que compreendemos quando observamos a arte fruto deste processo, o cinema. À historiadora, ao historiador, cumpre tomar o filme em suas complexas relações como o corpo social, "por aquilo que testemunha", "integrando-o no mundo que o rodeia e com o qual se comunica necessariamente" (FERRO, 1995, p. 203). Esta afirmação foi feita por Ferro ainda em meados dos anos 1970, e mantém-se válida, do mesmo modo que aquela de NÓVOA: no momento em que o historiador ou a historiadora puderam observar o filme para além do prazer estético e do divertimento, perceberam sua capacidade de impactar a sociedade e também como registro (2008: 25). Mais recentemente foi preciso enfatizar o aspecto de manipulação intrínseco à elaboração da obra fílmica (NAPOLITIANO, 2005, p. 243), o que torna mais complexa sua leitura. O que devemos considerar, entretanto, é que assistir a um filme significa, também, inventar significados, ultrapassando intenções dos seus agentes diretos (RAMOS, 2002, p. 296). No loop da montanha russa de fins do século XX até agora, com seus trilhos substituídos pelo leito do rio ou pelas ondas do mar, nessa fluidez contemporânea, o que buscamos é construir sentidos a partir do que vemos.

Algumas destas características coetâneas, sobretudo a fluidez, a volatilidade, a velocidade estão presentes e dão forma à obra cinematográfica escrita e dirigida por John Cameron Mitchell, Shortbus, produção estadunidense lançada em 2006. Em uma Nova Iorque fraturada pelo atentado às Torres Gêmeas do World Trade Center em 11 de Setembro de 2001, sujeitos que seriam considerados (ou são, por distintos setores desta sociedade conservadora globalizada) abjetos, desviantes de uma norma de vivência dos 
padrões eróticos e de gênero, se juntam no pequeno ônibus amarelo dirigido pela transgênera Justin Vivian Bond. Os percursos do corpo, a cidade, o desejo, a procura e o encontro (possível, mas nem sempre atingido) norteiam a narrativa polifônica da obra (AZEVEDO, 2016, p. 117ss). Diante da catástrofe, seja a ampla e nem sempre claramente perceptível da globalização, ou, aquela específica, da destruição da cidade e morte de seus habitantes, a busca pelo conforto (possível, aparente) do microscópio, expresso na pequena comunidade, no bairro, no arranjo do que até poucos anos atrás se configurava como um gueto, se mostra um caminho aberto a ser trilhado, garantindo alguma segurança (CASTELLS, 1992).

Shortbus é uma obra na qual podemos ouvir a polifonia de seus agentes. Isso se dá ao percebermos outros realizadores homenageados pelo diretor, ali referenciados, especialmente aqueles do cinema extremo dos anos 1970 (HEICHENBACH, 2010) repleto de sexo real ou simulado, mas, sobretudo, ao considerarmos o que se confirma nos créditos, e dá forma à película: o enredo e as personagens foram desenvolvidas com o elenco, a partir de testes, oficinas, vivências.

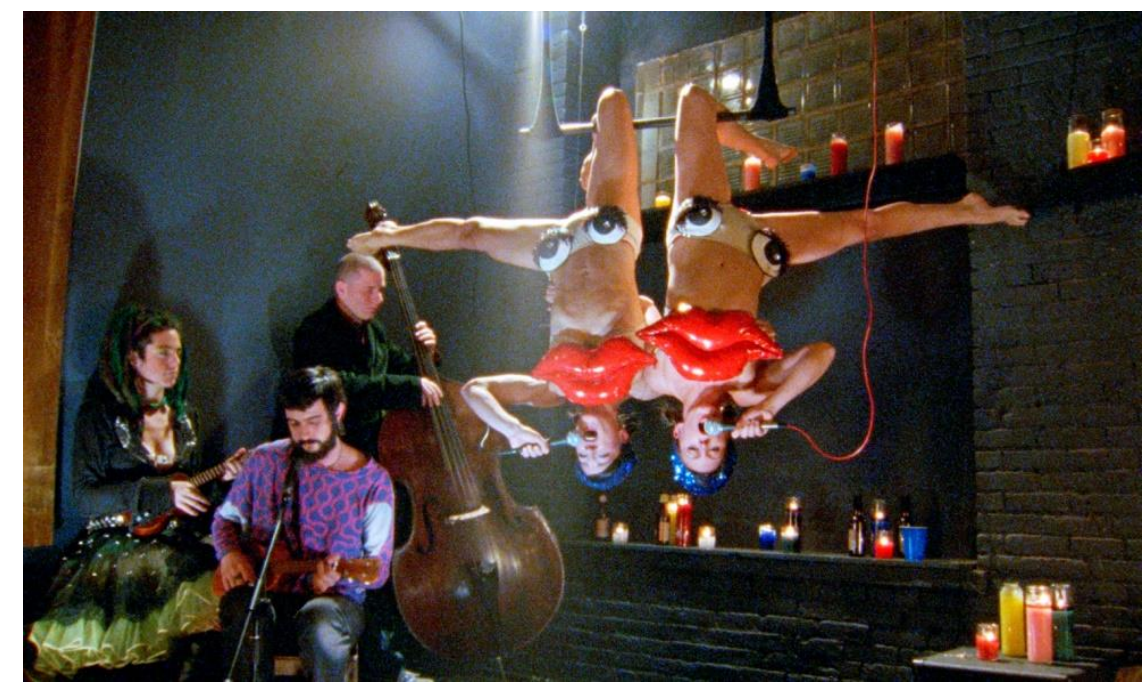

Imagem 1: capa do DVD de Shortbus

A obra apresenta sujeitos, em parceria ou solitariamente, em conflito e incompletude, criando simulacros de prazer, desejo, afeto. As personagens parecem trazer nisto, entretanto, certo mal-estar, levando à medicalização dos humores. Em um lugar, porém, encontros são estabelecidos. "É nos lugares e a partir deles que os impulsos e desejos humanos são gerados e incubados, que vivem na esperança de se realizarem, que se arriscam a se frustrar e, na verdade, com muita frequência, se frustram." (BAUMAN, 2004, p. 
125). No bar/happening Shortbus as relações podem assumir outro peso, outro tempo. Ali, no pequeno espaço ocupado por aqueles que têm sido subalternizados por sua classe, gostos, desejos, corporalidades, os sujeitos buscam romper sua impermeabilidade, para atravessar-se de outros. Isso acaba por fazer ver o que Bauman articula como ambivalência da cidade e dos sujeitos na cidade, no sentido de que comportam, ambos e em si, o desejo e o encontro com as diferenças e, ao mesmo tempo, repele-se o encontro com o outro que é marcadamente distinto, buscando a segurança das comunidades de semelhança.

Mixofobia e mixofilia coexistem em toda cidade, mas também dentro de cada um de seus habitantes. Trata-se reconhecidamente de uma coexistência problemática, cheia de som e fúria, embora signifique muito para as pessoas que se encontram na ponta receptiva da ambivalência líquido-moderna. (BAUMAN, 2004, p. 136)

As relações dos sujeitos desenroladas nos grandes centros urbanos são modificadas pelo trauma do ataque às Torres Gêmeas em 11 de setembro de 2001. Obviamente isto está hipertrofiado na cidade na qual se desenvolve o enredo de Shortbus, Nova lorque. Assomados pelo medo, a mixofobia de Bauman assume proporções paralisantes para aquelas personagens. Busca-se a cidade segura, impenetrável. Impenetráveis assumem ser também os sujeitos. No pequeno bar/ônibus dirigido por Bond o encontro com aquele que é diferente pode ser mais uma vez experimentado; há uma segurança possível. Ali, portanto, a busca pelo encontro erótico, pela performance liberada, encontra guarida na fluida superação da desconfiança frente ao outro.

Os sujeitos que transitam por esse bar são tornados pelas lentes de Mitchell muito distintos: visualmente fortes, em situações inusitadas, em idades variadas. Uma das salas desse bar é destinada especificamente aos atos sexuais. O espaço é pequeno, dividido por muitos, gerando interação entre os casais ou grupos ali presentes. Alguns são participantes ativos nestes atos, outros o fazem assistindo às cenas de sexo que ali se desenrolam. 


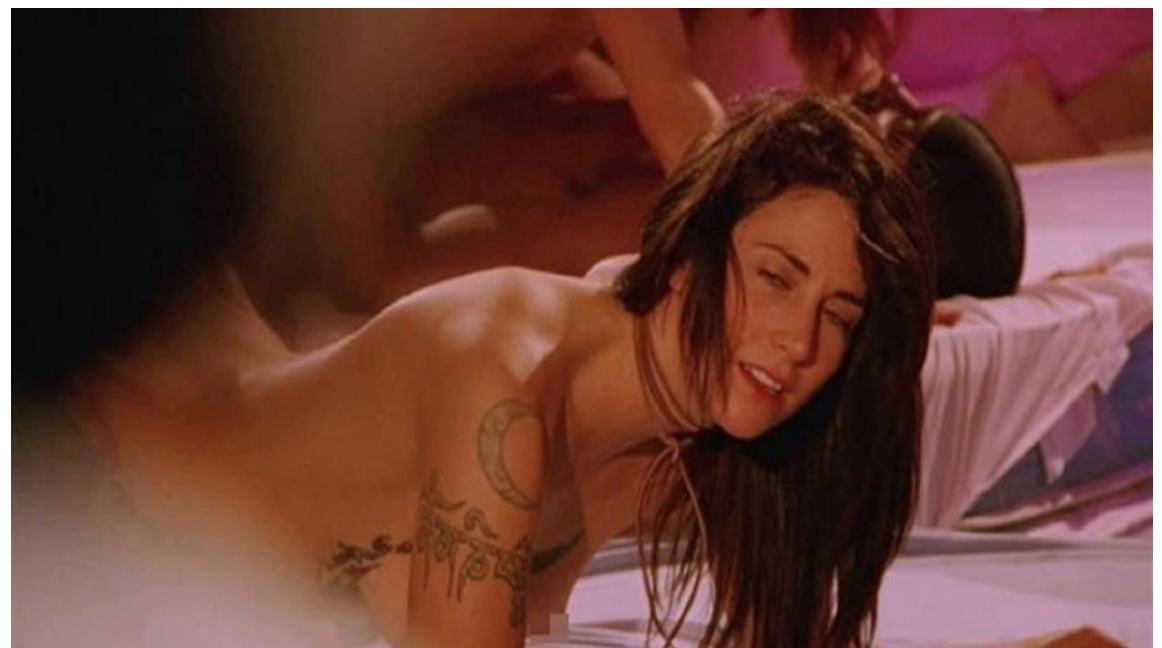

Imagem 2: detalhe de cena na sala destinada ao sexo no Shortbus

O casal formado por Sofia (Sook-Yin Lee) e Rob (Raphael Barker) é apresentado em uma pequena maratona de posições eróticas. Rob é um jovem desempregado, que realiza trabalho voluntário e que suporta o peso de se relacionar com Sofia, que não teve, até então, orgasmo. Sofia é uma terapeuta de casais pré-orgásmica. Em que pese sua ocupação profissional, ela imagina esconder de Rob que não teve ou tem orgasmos. Ocasionalmente a tensão entre os dois irá aparecer, imbricada com outros elementos.

Sofia será integrada às demais personagens por meio do contato com James (Paul Dawson) e Jamie (PJ DeBoy), o casal homossexual que a procura com o objetivo de abrir o relacionamento a um terceiro componente, ainda ignorado. Na sequência inicial vemos James em distintas posições, com e sem ereção, gravando imagens de seu corpo, suas reações, seus olhares. Quando ele consegue chegar ao orgasmo numa difícil autofelação, espalhando esperma em sua boca, por sua face, vemos a expressão de espanto no rosto de Caleb, o vizinho voyeur que o observa do apartamento do outro lado da rua, e James, em seguida ao gozo, chora. James tem objetivos que apenas serão apresentados posteriormente: o que ele faz, gravando tais cenas, é compor uma declaração do amor (a ser vista postumamente) que ele não consegue expressar por palavrar ao seu companheiro. A câmera é a mediação nesta relação, uma vez que, marcado pelo medo de viver em uma sociedade violenta e na qual não se pode confiar, esse sujeito volta-se para si, narcisicamente, impedido que está de estabelecer laços duradouros (LIPOVETSKY, 2007, p. 293-295): onde ele não consegue chegar, imagina que sua imagem possa. A brincadeira erótica é encerrada com a chegada de Jamie. Interessado no corpo suado do parceiro, se insinua para o sexo, mas recebe a fria informação: "desculpe, acabei de gozar". 


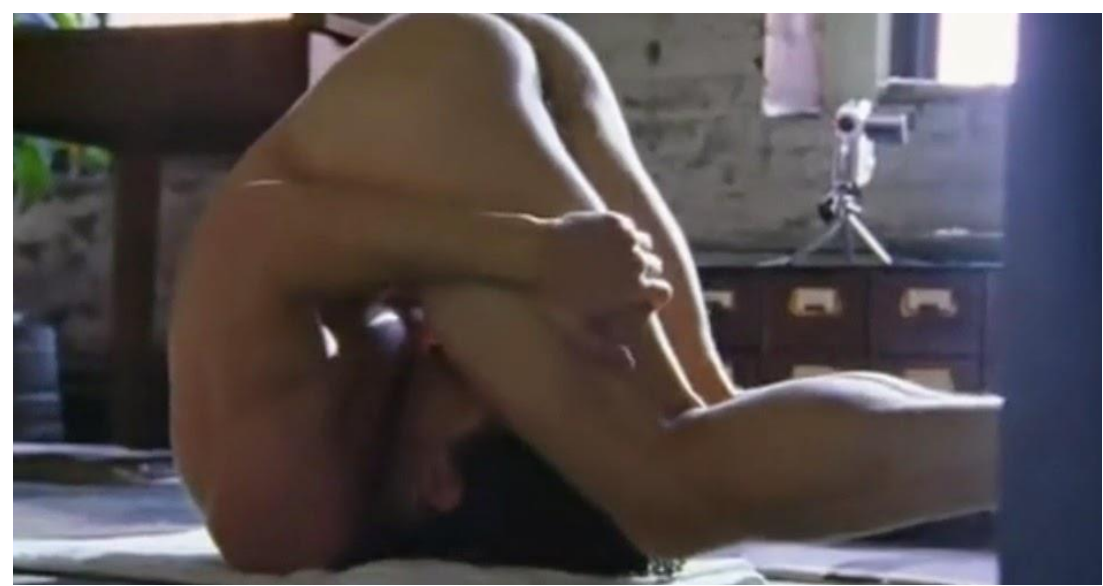

Imagem 3: James, na sequência inicial, em autofelação

Caleb é um rapaz jovem, usa bicicleta e aparelhos eletrônicos modernos, e observa o casal por meio de uma câmera. Ele segue James e Jamie, ouvindo suas conversas, antes de se apresentar a eles. A tecnologia é utilizada para caracterizar o que é negativo, como o medo de Caleb de se relacionar, não é apresentada como elemento que possa aproximar os sujeitos (TINKCOM, 2011).

Os dois, James e Jamie procuram Sofia, participando de uma sessão terapêutica bastante embaraçosa. Jamie apresenta a ambos com o mesmo nome e tem que ser lembrando que o parceiro voltou a usar James, não mais Jamie. Além disso, Jamie responde por ambos, até ser interrompido e solicitado que deixe a sala, momento em que Sofia pode perguntar a James o que o traz ali. O ex-garoto-de-programa e salva-vidas passa a narrar a morte de um frequentador do clube, afogado em seu horário de trabalho e podemos perceber o impacto daquela morte na trajetória de James. Um início de blecaute (uma referência subjacente aos ataques de 11 de setembro de 2001, expressão da insegurança que permanece a partir de então) traz Jamie de volta à sala. A sós com Sofia, Jamie caminha rapidamente para um diálogo irascível encerrado com um tapa no rosto que a terapeuta lhe oferece. A cena, tensa, ganha humor quando a terapeuta, sentada no sofá, se desculpa informando: "sou pré-orgásmica", ao que Jamie pergunta: "isso significa que você está tendo um agora?". Não, a terapeuta não estava atingindo o orgasmo. O casal convida Sofia para o bar/happening Shortbus, imaginando que o local e suas atrações pudessem auxiliar na resolução do que se apresentava ali como um problema. É intrigante a personagem constituir-se profissionalmente como uma terapeuta de casais que não consegue, entretanto, chegar ao orgasmo numa sociedade pós-revolução sexual. Talvez a busca pelo orgasmo exclusivamente no sexo seja o problema a ser enfrentado. Lipovetsky afirma: 
Não nos enganemos: o que impede a realização libidinal não são as normas atléticas do sexo (...). A satisfação que se tira da vida sexual não é apenas função do número de orgasmos: está ligada ao desejo do outro, aos laços de cumplicidade, ao charme da sedução, a intensidade dos sentimentos experimentados pelo outro. (LIPOVETSKY, 2007, p. 304)

No percurso que faz nas salas do Sohrtbus, guiada por Vivian, Sofia encontra Severin (Lindsay Beamish). A jovem é uma dominatrix com dificuldade para lidar com as pessoas. $\mathrm{Na}$ sequência em que é apresentada aos expectadores, ela está atendendo a um cliente, Jesse (Adam Hardman), um jovem amarrado na cama, sendo açoitado, e perguntando à dominatrix o que ela acha da reprodução... Em seguida, falando sobre o orgasmo, Severin afirma que o seu último foi bom, pois estava escuro e ela estava sozinha e o mundo parou. “E agora?" pergunta Jesse, enquanto Severin vê o esperma que, lançado em jatos pelo cliente, se juntou aos traços de uma pintura abstrata sobre a cama. "Eu não estava sozinha, e o mundo não parou". A resposta, dada sem ênfase, acompanhada de uma expressão branda e levemente dolorida, dá conta da sua desilusão.

Um dos frequentadores do cabaré é Ceth (Jay Brannan), um jovem modelo que ingressará na relação de James e Jamie. Antes, porém, ele é visto utilizando um pequeno aparelho, Yentha, precursor dos aplicativos de busca por parceiros. O aparato, entretanto, faz vibrar o marca-passo de Tobias (Alan Mandell). Após o encontro dos dois, um jovem e um idoso, ocasionado por um quase ataque do coração, os dois conversam. Tobias pergunta o que traz Ceth ali, para Nova lorque, e diz que aquela cidade era uma cidade sã, razão pela qual as pessoas, apesar dos altos aluguéis, continuam afluindo para lá. Essa sanidade, segundo Tobias, era fruto da tolerância dos nova-iorquinos. E conta que foi prefeito dali quando do surto HIV/Aids e como foi cobrado por não ter feito o suficiente porque estava "no armário", ainda. A expressão de dor no rosto de Tobias é substituída por outra, de aceitação, mas, mesmo assim, ele aparenta fragilidade ao dizer que as pessoas seguem ali, também para serem perdoadas... Ceth, cada vez mais próximo, beija Tobias, abraça-o. Perdoa-o. Um pequeno blecaute faz com que o clima intenso havido entre os dois seja dispersado. Mais uma vez, o medo, a distância.

James e Jamie convidam Ceth para sua casa. Nada incomum, já que estamos tratando de relacionamentos fluidos em mundo volátil e entre figuras que historicamente produziram discursos contrários à monogamia, ao patriarcado, ao nucleamento familiar binário, à posse de um sobre o outro. Os diversos movimentos de afirmação Igbtqi ${ }^{+}$foram 
também responsáveis pela crítica de costumes. Há ali um acordo, ao que parece, da monogamia, foi alterado para outro, ou seja, para aquele da abertura da relação a uma terceira figura.

A presença de Ceth entre James e Jamie traz, inicialmente, desconforto. Os três são retratados calados, olhando curiosos e desviando o olhar em seguida, para não serem pegos nessa inspeção do outro. Ceth anuncia sua saída da residência do casal e, diante dos protestos deles, permanece. Deste ponto em diante, o clima entre os três caminhará para a descontração e, finalmente, para o intercurso sexual. Uma das cenas cômicas da película é justamente essa. Os três, nus, se deliciam com os seus corpos. James está deitado, recebendo sexo oral de Ceth, enquanto o masturba: "Troque de mão, por favor? Prefiro com a esquerda", pede Ceth. Jamie participa realizando anilingus em Ceth. Ao dizer algo enquanto realiza tal prática, o novo parceiro Ihe pede que continue falando, que aquilo Ihe traz muito prazer. Jamie, em atenção ao que Ihe é solicitado, começa a cantar o hino nacional estadunidense enquanto lambe o ânus de Ceth. A cena, observada com espanto pelo vizinho voyeur, Caleb, é encerrada com os três rindo no tapete da sala. Bevin Yeatman aborda a referida cena a partir de seu aspecto humorístico, aproximando o olhar assustado de Caleb com o olhar do expectador, que também pode achar mais que inusitado aquele ato erótico, não bastasse ser realizado apenas por pessoas de um mesmo sexo, uma prática ora menos usual, ainda acompanhada por um símbolo patriótico (YEATMAN, 2008). E o sexo continua, encerrado pela penetração de Jamie em Ceth, incitado por James.

Em uma de suas idas ao Shortbus, agora acompanhada de Rob, Sofia e o amante iniciam um jogo: ela insere um vibrador em formato de ovo na vagina e lhe entrega o controle remoto. O que seria agradável gera uma série de conflitos quando Rob perde sua parte do aparelho, que passa de mão a mão, sem que as pessoas saibam o que é. Enquanto isso, em um dos quartos, Severin e Sofia se aproximam e a dominatrix, sentindo o vibrador em Sofia, se aproveita da sensação e chega ao orgasmo: "Desculpe, sou muito sensível". O estrago já estava feito: a terapeuta se sente objetificada, incapaz... Em outra cena, Sofia e Justin Bond se beijam carinhosamente. Tudo vai bem, até que o ovo começa a vibrar. Justin, ao perceber o que está ocorrendo, citando um seu amigo, diz: "Antes eu queria mudar o mundo, agora só quero sair daqui com alguma dignidade". E deixa Sofia. 
Encolerizada, Sofia segue em busca de seu companheiro. No meio do caminho é interpelada por Caleb, que a culpa pela introdução de uma terceira pessoa na relação entre James e Jamie: Sofia, com o corpo aos solavancos pela sensação trazida por aquele ovo, Ihe aplica diversos golpes. A terapeuta encontra Rob, acha o controle, sai do bar, arranca da vagina o ovo e lhe dá pancadas com uma perna de manequim retirada da decoração do bar, pondo fim àquela maratona em busca de alguma satisfação. Mais uma vez, Lipovetsky pode ser chamado à fala, auxiliando-nos a compreender o fenômeno:

... nossa cultura nos impõem metodicamente experimentar tudo, livrar-nos de nossos bloqueios e inibições, gozar ao máximo, tornar-nos uma espécie de atletas da libido. Sob a aparência da permissividade, progrediria, de fato, a ferocidade das normas da excelência mensurável, um hedonismo quantitativo e obrigatório mais eficaz em produzir complexo do que em desinibí-los. (LIPOVETSKY, 2007, p. 292)

Assomada por seus sentimentos, Sofia deixa o lugar. Rob e Severin também o fazem, e buscam um lugar para o sexo, e ele poderá gozar sendo submetido pela dominatrix, em uma relação mais satisfatória do que aquela sobre a qual paira o peso do não-gozo. $\mathrm{Na}$ confusão, James também deixa o bar.

O lugar procurado por James é o clube no qual trabalha. Ali, coloca na câmera gravadora uma fita, destinada a Jamie. Toma uma grande quantidade de tranquilizantes, insere sua cabeça em um saco plástico que amarra ao pescoço, e entra na piscina rumo à morte. Nesse ponto se pode entender a abertura do casal para outrem: James queria que Jamie tivesse algum amparo quando de sua morte, e achava que já tinha encontrado esse sujeito na figura de Ceth. O voyeur, entretanto, não deixará que o ato se consume. Caleb retira James da piscina, chama uma ambulância. Enquanto o socorro não chega, ele deixa seu número telefônico escrito na face de James.

\section{Gozos}

Jamie e Ceth estão no apartamento do casal, ligando para os hospitais. Não encontram James. Passados tempo e algumas ligações, um dos hospitais informa que James esteve ali, mas fugiu. Isso acontece quando ele acorda e encontra a funcionária ("vigia de suicida") dormindo. No espelho, devastado, vê o número de Caleb e liga. Deixa em seguida o hospital. A frustração de Jamie é imensa, sobretudo porque, buscando informações possíveis para o desaparecimento de James, encontra no computador do amante o vídeo a ele destinado. E nesse momento entende que seu companheiro, com quem divide parte da vida, 
tem a vida alterada por uma depressão aparentemente incurável, mesmo estando medicalizado.

Enquanto Rob e Severin transam em algum hotel da cidade, uma Sofia alienada tenta atender um casal em terapia. A pequenez dos embates entre esposo e esposa auxiliam a levar a Sofia a um estado mental mais confuso e, ao mesmo tempo, determinado: a sair dali. Em uma fuga mental e física, a terapeuta deixa o casal e segue para a mata. Em um banco à margem d'água ela se deita e busca o orgasmo sozinha.

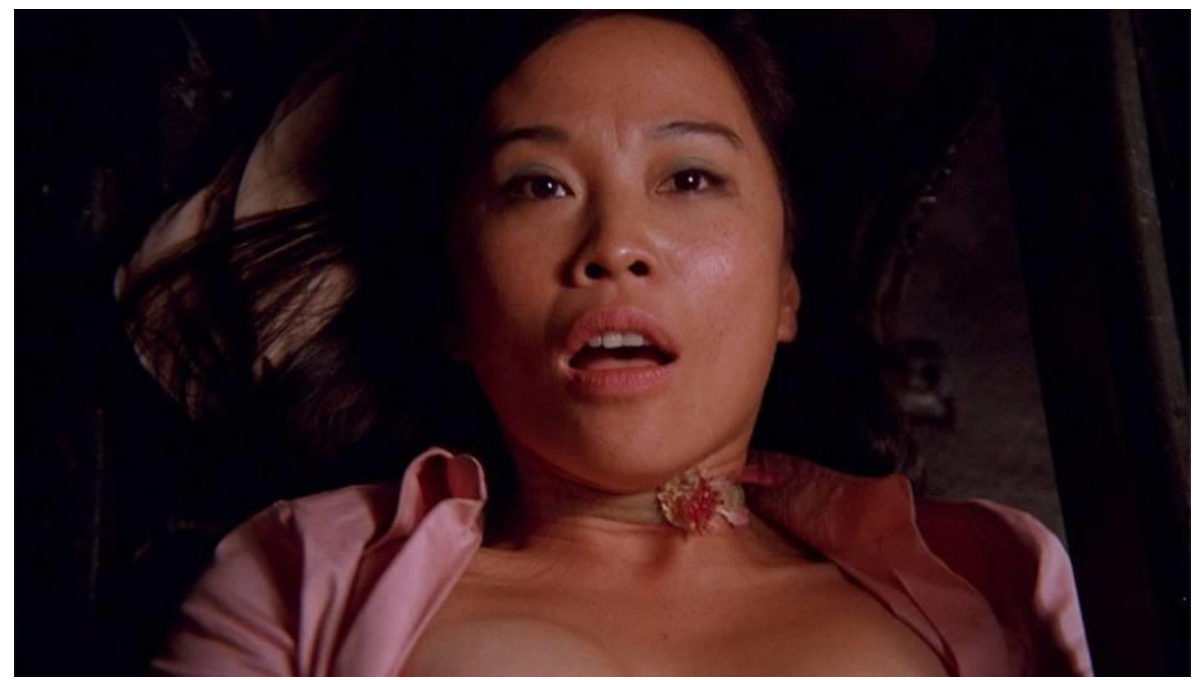

Imagem 5: Sofia, em busca do orgasmo

James vai para o apartamento de Caleb. Ali, descobre que é, ao lado de Jamie, objeto do voyeurismo do vizinho. Deita-se em sua cama, descansa. Enquanto isso, Caleb se aproxima, amedrontado, mas segue. O diálogo travado entre James e Caleb é tenso. Se, enquanto está trancado no bar com Severin descobrimos que James foi prostituto, é enquanto está com Caleb que descobrimos que ele não se deixa penetrar. Não apenas não permite que outro sujeito penetre seu ânus durante a relação sexual, mas sentimentos não penetram em sua mente. "Tudo para na minha pele, não entra. Não sinto nada.". Caleb busca sua boca, seu corpo. James, enfurecido, se nega: “Eu não quero sentir!". Entretanto, permite. Caleb Ihe penetra. Com o ânus penetrado, outras barreiras parecem ceder. Quando o vizinho voyeur deixa o apartamento para comprar velas que fizessem frente a um novo e mais prolongado beclaute, ele aparece à janela e é visto, calmo, por Jamie.

Na próxima sequência, James, Jamie, Caleb e Ceth entram no Shortbus. O bar está todo iluminado por velas, cuidadosamente acesas pela anfitriã. Rob e Severin estão ali. Sofia 
entra em seguida, com as roupas amarfanhadas, o rosto um pouco sujo. Ela se mantém distante de todos, apenas cumprimentando de longe os que conhece, inclusive Rob.

Um casal chama a atenção de Sofia desde sua primeira incursão naquele bar. Ele é formado por Nick (Jan Hilmes) e Leah (Shanti Carson). Os beijos lascivos, o sexo calmo e constante, as expressões de prazer haviam chamado sua atenção. São eles que a veem e a cumprimentam. Em seguida, sentam-se ao seu lado, um à esquerda e outro à direita. Leah limpa seu rosto e Ihe beija. Nick também a beija.

No bar, Justin Vivian Bond (ao centro, na imagem abaixo) acompanhada de The Hungry March Band, em um figurino diáfano, entoa uma canção da banda Linkin Park, In the end, de maneira intimista. Estão todos ao seu redor, não há luz, por isso sua voz é suave, na ausência de microfones.

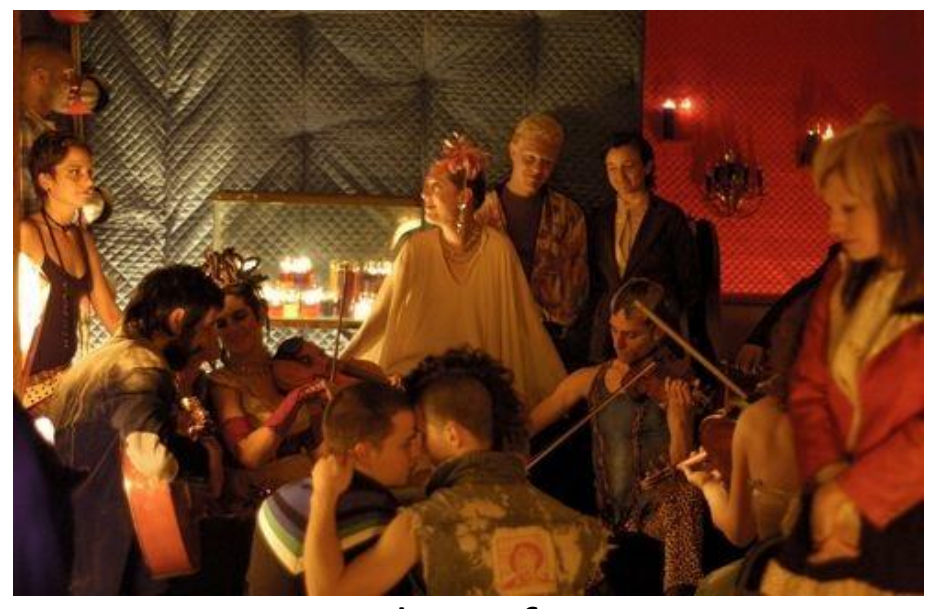

Imagem 6

As personagens parecem gradativamente se aproximar, diante da cena, da música. Beijos são vistos em volume, corpos roçando em outros corpos. A visão de Sofia naquele banco à margem, com a maré subindo, alterna-se com a do bar. Uma pequena banda entra pelo bar, batendo seus metais e dando um visual circense ao ambiente. O clima intimista dá lugar ao dionisíaco. A cantora substitui sua pequena voz por outra, aumentada por um megafone. Sofia, beijada ali pelo casal, sofregamente, no banco distante ela chega ao orgasmo - ou naquela sala? Severin gargalha, os corpos se misturam. Com o gozo, a luz retorna. O trauma é superado - ou suspenso. A vida se insinua mais uma vez. E importante ressaltar que a função do gozo para as personagens não está presa ao caráter orgástico, mas ao sentido da conexão com o outro, a partir de uma experiência sensório-corporal, político/afetiva, uma busca pela alteridade perdida em tempos fraturados e líquidos. 
Tempos em que para seguir em frente é preciso se expor, se entregar ao toque e ao cuidado do outro, se deixar penetrar e partilhar sensações e experiência que só o corpo alheio ou não pode proporcionar. Como ensinou Lacan, "Gozar é usufruir de um corpo. Gozar é abraçá-lo, é estreitá-lo, é picá-lo em pedaços" (LACAN, 2012, p. 31). É esse sentido utópico/ libertário que a personagem Justin Vivian Bond e próprio diretor do filme Mitchell procuram rememorar a partir daquele lugar - identificado por Mark Olsen, como "retrato idealizado sobre um tempo e um lugar específicos, onde cada um luta para encontrar um sentido na sobrevivência de cada dia" (capa do DVD de Shortbus).

No espaço globalizado diagnosticado por BAUMAN (2001) o desengajamento parece ser a tônica. Enquanto Edward MacRAE (1990) apontava na passagem dos anos 1980 para a década seguinte para um processo de transformação que passava pelo indivíduo e pelo coletivo (que podemos compreender como uma trajetória que dá sentido ao "eu", na medida que leva em consideração o "outro" na disputa por territorialidades alternativas, por outras vivências e possibilidades), Bauman sugere um espaço marcado por uma aparência homogênea.

Mesmo os diferentes se tornam bastante parecidos, sobretudo porque todos são lançados num turbilhão temporal que nos transforma em uma massa sem características definidas. E afirma BAUMAN: "os sólidos que estão para ser lançados no cadinho e os que estão derretendo neste momento, o momento da modernidade fluida, são os elos que entrelaçam as escolhas individuais em projetos e ações coletivas" (2001, p. 12).

A supervisibilidade dos grupos definidos por afetividades não hegemônicas e/ou por performances de gênero alternativas àquelas oriundas do binarismo homem/mulher, que em outro momento foram dissonantes da norma, parece não alcançar mais o seu sentido desagregador da ordem vigente, mas serviu para empapar os olhares e torná-los parte de uma paisagem deformada pela alta velocidade do trem em movimento. Higienizados, não têm qualquer possibilidade de chocar. Normalizados, tornados cada vez mais parecidos com os casais heterossexuais em seu comportamento e nas expressões da sexualidade e dos afetos, frequentam o horário nobre da TV.

Ao que tudo indica, estamos rodopiando no labirinto, sem que possamos perceber o entorno e, assim, escolher o caminho a seguir. Mesmo que seja um caminho que nos leve 
para mais uma parede ou outra encruzilhada, mas uma trajetória escolhida. O preço da alta velocidade da viagem é o enjoo.

A filósofa Olgária Matos afirma que esse tempo, nosso tempo, "é fatalizado pela ordem das urgências que significa uma oscilação na razão instrumental, o culto dos meios e o esquecimento dos fins. Ele é o reino das revoluções tecnológicas do progresso". Contudo, o que se verifica é a flexibilização cada vez mais intensa dos direitos sociais "e o cidadão travestido de consumidor, (...) acentuando a superficialidade dos vínculos e uma pobreza interior" o que nos levaria a um presente perpétuo (MATOS, 2009, p. 106).

Se observamos os grupos sociais apenas a partir de suas performances de gênero ou gostos eróticos, sobretudo midiatizados, talvez possamos ver ali com mais facilidade esse consumidor travestido de cidadão. Na lógica do capital, mesmo aqueles e aquelas que, em um determinado momento ferem as susceptibilidades burguesas, são absolvidos de tal pecado, basta que consuma. A indulgência tem seu preço.

Mas, ao observarmos mais de perto, inserindo outros elementos em nossos recortes, podemos nos fiar em LASTÓRIA, que observa: "vivemos um estado de violência" (2010, 77-94); a linguagem marcada pela ausência de interlocutores, cuja mediação simbólica dos conflitos fica entregue a apenas um controle formal do direito liberal que, sob o manto da igualdade, deixa se conduzir por uma lógica hedonista. Quando viramos a página, podemos ver as vítimas do engodo, sobretudo quando voltamos para o Brasil, país onde se mata por questões de gênero diariamente. Não apenas a eliminação física deve ser contada aí, mas a eliminação gradativa e simbólica a que estão submetidos mulheres e integrantes da população formada por gays, lésbicas, bissexuais, travestis, transexuais, transgêneros e outros mais. Agreguemos a esses números aqueles violentados por sua raça/etnia, por sua classe social.

Em um tempo menos liquefeito, sujeitos que não se enquadravam na lógica binária das performances de gênero ou que rompiam com a heterossexualidade compulsória, construindo outros corpos, outras experiências, outros afetos e eróticas, foram tomados como inimigos: pecado, crime ou patologia foram impingidos ao cerne daqueles seres e, por conseguinte, fogo, forca ou encarceramento vieram como remédios da alma, da índole, da mente. 
Em tempos mais sólidos, tais sujeitos foram considerados inimigos. De quem? Daqueles sujeitos e grupos sociais instalados hegemonicamente nesta sociedade global. Inimigos devem ser punidos, eliminados. Temos vivido em uma sociedade que se organiza em oposição. Ideias são opostas umas às outras, assim como nações, que são submetidas como resultado final da oposição. Grupos sociais e sujeitos também estão inseridos nesta lógica.

Em tempos mais céleres, apenas tornamos a violência menos inquietante, a morte menos feia, a exclusão menos impactante. Na prática, os inimigos ainda estão aí, sendo eliminados em massa, cotidianamente. Nessa transição, nem todas as relações foram de fato transformadas.

Um primeiro passo para a ruptura de tal modelo de relações (globais e microscópicas) é sua constatação. Em seguida, é preciso explicitar sua natureza violenta, excludente, sórdida. Há e haverá resistência dos grupos sociais que ocupam o topo da pirâmide. É e será preciso continuar o percurso e movê-los de onde estão. A partir de então, podemos recuperar experiências outras, na sua diversidade, e colocá-las em diálogo, para que possamos compreendê-las, não as eliminar. Conviver, algo mais importante que vencer.

ŽlŽEK, refletindo sobre a sexualidade em nossos dias (2014, p. 38ss), aponta para determinados limites da maneira como vivemos. Tomando o exemplo da Masturbatona, evento ocorrido em Londres no qual os sujeitos se reuniam para se masturbar, numa grande maratona, torna explícita a solidão, inclusive a do sexo, na medida em que as pessoas se reuniam, em público para se masturbar, mas não para, juntos, atingirem o gozo. Cada qual em seu pequeno espaço, só consigo mesmo, ao invés de aproveitarem a oportunidade para, mais que transformar a masturbação em um happening, se encontrarem, aproveitarem seu corpo e os demais corpos interessados na partilha do gozo. Mitchell e seus atores buscam o encontro, em dupla, trio, pequenos grupos. Não só observar, mas encontrar-se e aos demais na coletividade, ou seja, uma aposta na mixofilia.

Shortbus faz rir de pessoas que podem gozar, que podem exercitar sua sexualidade em uma metrópole no mundo capitalista desenvolvido, mas não conseguem fazê-lo. Certamente porque a questão não é mais essa, de gozar ou não, ou construir performances de gênero que tensionam com os modelos hegemonicamente instalados, já que isso - com maior ou menor resistência dos setores conservadores ou reacionários desta sociedade 
global -, está dado. Trata-se agora de conseguir intimidade consigo e com o outro. Aí está o nó a ser desatado.

Há quem, ao ler este texto, diga que se trata de uma utopia. Por certo, considerando como utopia o que ainda não se transformou em realidade. $O$ que se apresenta como expectativa, esperança ou temor pode deixar de ser objeto do futuro e se tornar presente. Segundo DILTHEY, o presente é o preenchimento de um momento temporal com realidade, ele é realidade em oposição à lembrança ou às representações do porvir (2010, p. 107). Se os dados estão rolando, a aposta é no preenchimento desse tempo por uma realidade de luta da qual emerja uma sociedade em que uma cultura de convívio seja hegemônica, cessando a ascensão deste reacionarismo em escala global, na qual a constituição subjetiva queer possa estar assente nos direitos humanos colocados em um patamar mais importante que aquele que vemos hoje.

\section{REFERÊNCIAS BIBLIOGRÁFICAS}

ANDRADE, Mário de. Contos novos. São Paulo: Livraria Martins, 1947.

APÓS PROTESTO, mostra com temática LGBT em Porto Alegre é cancelada. Folha de S. Paulo, Ilustrada. Disponível em http://www1.folha.uol.com.br/ilustrada/2017/09/1917269-apos-protestomostra-com-tematica-lgbt-em-porto-alegre-e-cancelada.shtml. Consultado em 28 Jan. 2018.

AZEVEDO, Adriana Pinto Fernandes de. Reconstruções queer - por uma utopia do lar. Tese (Doutorado em Literatura, Cultura e Contemporaneidade). Programa de Pós-Graduação em Literatura, Cultura e Contemporaneidade, Departamento de Letras da Pontifícia Universidade Católica do Rio de Janeiro, 2016.

BAUMAN, Zygmunt. Modernidade Líquida. Rio de Janeiro: Zahar, 2001.

BAUMAN, Zygmunt. Amor líquido: sobre a fragilidade dos laços humanos. Rio de Janeiro: Jorge Zahar Ed., 2004.

CASTELLS, Manuel. O poder da identidade. São Paulo: Paz e Terra, 1992.

COLI, Jorge. Sexo não é mais o que era. In: NOVAES, Adauto (org.). Mutações: o futuro não é mais o que era. São Paulo: Edições Sesc SP, 2013, p. 429-457.

DILTHEY, Wilhelm. A construção do mundo histórico nas ciências humanas. São Paulo: Unesp, 2010.

FERRO, Marc. O filme: uma contra-análise da sociedade? In: LE GOFF, Jacques \& NORA, Pierre. História: novos objetos. 4 ed. Rio de Janeiro: Francisco Alves, 1995, p. 199-215.

HEICHENBACH, Carlos. Anais do cinema extremo. Ilustríssima. Folha de S. Paulo, 22/08/2010. Disponivel em http://www1.folha.uol.com.br/fsp/ilustrissima/il2208201004.htm. Consultado em 2 Mar. 2017. 
INTERAÇÃO DE CRIANÇA com artista nu em museu em São Paulo gera polêmica. Disponível em https://g1.globo.com/sao-paulo/noticia/interacao-de-crianca-com-artista-nu-em-museu-de-sp-gerapolemica.ghtml. Consultado em 28 Jan. 2018.

JESUS, Carolina Maria de. Quarto de despejo - diário de uma favelada. São Paulo: Francisco Alves, 1960; MARÃO, José Carlos \& RIBEIRO, José Hamilton. Realidade Re-Vista. Santos: Realejo, 2010.

KRISTEVA, Julia. Poderes de la perversión - ensayo sobre Loius-Ferdinand Céline. 6. ed. México: Siglo $X X I, 2006$.

LACAN, Jacques. O Seminário, Livro 19. Rio de Janeiro: Jorge Zahar.

LASTÓRIA, Luiz Antônio Calmon Nabuco. Sociedade, linguagem e subjetividade. In: Lastória, L. A. C. N.; Pucci, B.; Zuin, A. A. S.. (orgs.). Teoria Crítica e Inconformismo. Campinas: Autores Associados, 2010, p. 77-94.

LEAL, Aline. Ministra pede investigação e punição de autores de adesivos ofensivos a Dilma. EBC. Disponivel em http://www.ebc.com.br/noticias/2015/07/spm-pede-investigacao-e-punicao-deautores-de-adesivos-ofensivos-dilma. Consultado em 31 Jan. 2018.

LIPOVETSKY, Gilles. A era do vazio: ensaios sobre o individualismo contemporâneo. Barueri: Manole, 2005.

LIPOVETSKY, Gilles. A felicidade paradoxal: ensaio sobre a sociedade do hiperconsumo. São Paulo: Companhia das Letras, 2007.

MAcRAE, Edward. A construção da igualdade - identidade sexual e política no Brasil da "abertura". Campinas: Editora da Unicamp, 1990.

MATOS, Olgária. Contemporaneidades. São Paulo: Lazuli/Cia. Editora Nacional, 2009.

MC Linn da Quebrada. Trip TV. Disponível $\quad$ em https://www.youtube.com/watch?v=A9KKFSyvlS4\&t=7s. Consultado em 14 Out. 2017.

NAPOLITANO, Marcos. A história depois do papel. In: PINSKY, Carla B. (org.). Fontes históricas. 2 ed. São Paulo: Contexto, 2008, p. 235-289.

NÓVOA, Jorge. Apologia da relação Cinema-História. In: \& BARROS, José D'Assunção (orgs.). Cinema-História: teoria e representações sociais no cinema. 2 ed. Rio de Janeiro: Apicuri, 2008, p. 1342.

OLIVEIRA, Peterson José. Dilemas sentimentais e identidade homoerótica: uma leitura de Frederico Paciência de Mário de Andrade. albuquerque - revista de história. vol. 7, n. 14. jul.-dez./2015, p. 627.

OS SEIS PARTIDOS de extrema direita mais votados na Europa. O Globo. Disponível em https://oglobo.globo.com/mundo/os-seis-partidos-de-extrema-direita-mais-votados-da-europa$\underline{19366693}$, Consultado em 14 Out. 2017.

POLÍCIA INVESTIGA HOMICÍDIO de travesti que foi espancada até a morte no CE. Disponível em http://g1.globo.com/ceara/noticia/2017/03/policia-investiga-homicidio-de-travesti-que-foiespancada-ate-morte-no-ce.html. Consultado em: 14 Out. 2017. 
RAMOS, Alcides Freire. Os Inconfidentes (1972, Joaquim Pedro de Andrade): recepção e historicidade. In: _ \& PATRIOTA, Rosangela (orgs.). História e Cultura: espaços plurais. Uberlândia: Asppectus/Nehac, 2002, p. 295-309.

RICH, L. Ruby. New Queer Cinema. Sight \& Sound. Publicado originalmente em Village Voice, 1992. Disponivel em http://www.bfi.org.uk/news-opinion/sight-sound-magazine/features/new-queercinema-b-ruby-rich. Acesso em 14 Out. 2017.

SEVCENKO, Nicolau. A corrida para o século XXI: no loop da montanha russa. São Paulo: Companhia das Letras, 2001.

SWAIN, Tania Navarro. Para além do binário: os queers e o heterogênero. Gênero, v. 2, n. 1, jul.-dez. 2001, p. 87-98.

TINKCOM, Mathew. "You've got to get on to get off": Shortbus and the Circuits of the Erotic. South Atlantic Quarterly. v. 110, n. 0 3, p. 693-713. Disponível em http://saq.dukejournals.org/content/110/3/693.short. Acesso em 14 Out. 2017.

YEATMAN, Bevin. Who laughs? A moment of laughter in Shortbus. A Danish Journal of Film Studies, n. .26 , dez. 2008, p. 62-71.

ŽIŽEK, Slavoj. Violência: seis reflexões laterais. São Paulo: Boitempo, 2014. 